University of Nebraska - Lincoln

DigitalCommons@University of Nebraska - Lincoln

Faculty Publications in Food Science and

Technology

Food Science and Technology Department

2018

In Vitro Digestibility of Nanoporous Wheat Starch Aerogels

Ali Ubeyitogullari

Sandrayee Brahma

Devin J. Rose

Ozan Ciftci

Follow this and additional works at: https://digitalcommons.unl.edu/foodsciefacpub

Part of the Food Science Commons

This Article is brought to you for free and open access by the Food Science and Technology Department at DigitalCommons@University of Nebraska - Lincoln. It has been accepted for inclusion in Faculty Publications in Food Science and Technology by an authorized administrator of DigitalCommons@University of Nebraska Lincoln. 


\title{
In Vitro Digestibility of Nanoporous Wheat Starch Aerogels
}

\author{
Ali Ubeyitogullari, Sandrayee Brahma, \\ Devin J. Rose, and Ozan N. Ciftci \\ Department of Food Science and Technology, University of Nebraska-Lincoln, \\ Lincoln, Nebraska 68588-6205, United States \\ Corresponding author — O. N. Ciftci, tel +1-402-472-5686; email ciftci@unl.edu \\ ORCID — Devin J. Rose 0000-0002-1333-6318
}

\begin{abstract}
This study reports the in vitro digestibility of starch aerogels for the first time. The relative crystallinities of the wheat starch aerogels (WSAs) produced at gelatinization temperatures of $120^{\circ} \mathrm{C}$ (WSA-120C), $130^{\circ} \mathrm{C}$ (WSA-130C), and $120^{\circ} \mathrm{C}$ with the addition of sodium metaphosphate (STMP) (WSA-STMP) and xerogel were similar. However, WSA-120C showed the highest amylose-lipid complex content. The addition of STMP created some cross-linked starch with a phosphorus content of $0.023 \%$. Resistant starch (RS) contents of WSA-STMP (33.5\%) and xerogel (26.9\%) were higher than the other samples when they were uncooked prior to digestion. Nevertheless, the RS contents of WSA-STMP and xerogel decreased drastically with cooking. RS contents of WSA-120C and WSA-130C were stable with cooking and provided 4.5- and 3.0-fold increases in the RS content, respectively. WSA is a promising functional food ingredient with a high RS content, even after cooking.
\end{abstract}

Keywords: wheat starch, aerogel, digestibility, resistant starch, supercritical, nanoporous

Published in Journal of Agricultural and Food Chemistry 66 (2018), pp 9490-9497.

DOI: 10.1021/acs.jafc.8b03231

Copyright (c) 2018 American Chemical Society. Used by permission.

Submitted June 20, 2018; revised August 9, 2018; accepted August 21, 2018; published

August 21, 2018. 


\section{Introduction}

Organic aerogels have been attracting interest for various food, nutraceutical, and pharmaceutical applications as a result of their high surface area and lightweight and porous structure. Recent studies have focused on the application of aerogels to enhance the solubility and/or bioavailability of poorly water-soluble bioactive compounds by impregnation into the aerogel matrix..$^{1,2}$ To illustrate, impregnation of vitamin $D_{3}$ into an alginate aerogel resulted in $20 \times$ higher solubility compared to the crude vitamin $D_{3}$ as a result of the decrease in the crystallinity caused by impregnation into the aerogel. ${ }^{3}$ Furthermore, inorganic silica aerogels have been extensively studied to improve and control the release of drugs, such as ketoprofen, griseofulvin, benzoic acid, and paracetamol. ${ }^{1,4}$ Among polysaccharide-based aerogels, starch aerogels have received much attention as a result of their low cost, renewability, stability upon storage, biodegradability, and biocompatibility. Recently, Garciá-Gonzaléz et al. ${ }^{5}$ investigated supercritical carbon dioxide $\left(\mathrm{SC}-\mathrm{CO}_{2}\right)$-aided impregnation of ketoprofen and benzoic acid into corn starch aerogels. Impregnated drugs had a less crystalline structure compared to their free forms, and impregnation into aerogels provided a controlled release in both simulated gastric and intestinal fluids. ${ }^{5}$

Wheat is a great source of starch to produce aerogels with extraordinary properties for food applications. ${ }^{6}$ In our previous studies, wheat starch aerogels (WSAs) were used to generate low-crystallinity phytosterol nanoparticles, ${ }^{7,8}$ where the solubility of the phytosterols was improved 37-fold compared to crude phytosterols by impregnation into the nanoporous WSAs. ${ }^{7}$ Although various aerogels have been produced with the aim of improving the bioavailability of lipophilic bioactives, none of those aerogels have been investigated for their digestibility, which is critical for not only the release of the bioactives but also the nutritional value of the aerogel matrix.

In recent years, there have been considerable research efforts to increase the resistant starch (RS) content of starches ${ }^{9-13}$ because of the potential of RS to improve human health by protecting against diseases, such as colon cancer, type 2 diabetes, and obesity. ${ }^{14-16}$ The rate and extent of starch digestion are affected by several factors, such as fine structure of amylopectin, surface morphology, porosity, 
amylose-lipid complexes, and crystallinity. ${ }^{17}$ The physical properties that affect starch digestion are likely influenced by starch aerogel production steps, namely, gelatinization, solvent exchange, retrogradation, and drying. ${ }^{6}$ Moreover, chemical modification of starch with sodium metaphosphate (STMP) affects not only the digestibility but also the physical properties. ${ }^{18}$ Our hypothesis was that the addition of STMP into the aerogels would affect the structure and also digestibility of the aerogels.

Therefore, the main objective of this study was to investigate the in vitro digestibility of WSA. Specific objectives were to (a) produce and characterize WSA by both gelatinization upon heating and using STMP as a chemical cross-linker and (b) investigate the effect of the surface area and chemical crosslinker on the digestibility of WSA. Wheat starch and wheat starch xerogels (air-dried) were also evaluated for their digestibility and compared to those of WSAs.

\section{Materials and Methods}

\section{Materials}

Wheat starch was kindly donated by Manildra Milling Corporation (Hamburg, IA, U.S.A.). Wheat starch was composed of $25 \%$ amylose and $75 \%$ amylopectin, as declared by the supplier. Food-grade STMP was obtained from Innophos (Cranbury, NJ, U.S.A.). Ethanol (100\%) was purchased from Decon Laboratories, Inc. (King of Prussia, PA, U.S.A.). $\mathrm{CO}_{2}$ (99.99\% purity) was supplied by Matheson Tri-Gas, Inc. (Lincoln, NE, U.S.A.). $\mathrm{KH}_{2} \mathrm{PO}_{4}$ (purity of $\geq 99 \%$ ) was purchased from MP Biomedicals, LLC (Solon, OH, U.S.A.). Thermostable $\alpha$-amylase (from Bacillus licheniformis, 3000 units $/ \mathrm{mL}$ ), amyloglucosidase (from Aspergillus niger, 3260 units $/ \mathrm{mL}$ ), and glucose oxidase-peroxidase assay kit were purchased from Megazyme (Bray, Ireland). Pepsin (from porcine gastric mucosa, $\geq 250$ units $/ \mathrm{mg}$ of solid) and pancreatin [from porcine pancreas, neutral protease, 208 United States Pharmacopeia (USP) units/mg of solid; $\alpha$-amylase, 223 units/mg of solid; and lipase, 38.5 USP units/ mg of solid] were obtained from Sigma-Aldrich (St. Louis, MO, U.S.A.). 


\section{Formation of Nanoporous Starch Aerogels}

Aerogels were produced according to the method of Ubeyitogullari and $\mathrm{Ciftci}_{1}{ }^{6}$ where the processing parameters were optimized for the highest surface area. Aerogel formation consisted of three main steps, namely, gelatinization, solvent exchange, and $\mathrm{SC}-\mathrm{CO}_{2}$ drying. Briefly, starch dispersions (10 wt \%) were gelatinized in a closed high-pressure reactor (4520 Bench Top Reactor, Parr Instrument Company, Moline, IL, U.S.A.) at $120^{\circ} \mathrm{C}$ with a mixing rate of $600 \mathrm{rpm}$ for $20 \mathrm{~min}$ to form a hydrogel. The hydrogels were stored at $4{ }^{\circ} \mathrm{C}$ for $48 \mathrm{~h}$, and then the water in the hydrogel was replaced with ethanol using a solvent exchange step to obtain an alcogel. Solvent exchange took place by soaking the hydrogels into $30,50,70$, and $100 \%(\mathrm{v} / \mathrm{v}$ ) ethanol solutions for $1 \mathrm{~h}$ and then keeping in $100 \%$ ethanol for $24 \mathrm{~h}$. Finally, the alcogels were dried in a custom-made laboratory-scale $\mathrm{SC}-\mathrm{CO}_{2}$ drying system at $40^{\circ} \mathrm{C}$ and $10 \mathrm{MPa}$ for $4 \mathrm{~h}$ to obtain the aerogels (WSA120C). Details of the $\mathrm{SC}-\mathrm{CO}_{2}$ drying system and its operation were reported previously. ${ }^{8}$

In addition to WSA-120C, the wheat starch dispersion (10 wt \%) was also gelatinized at $130^{\circ} \mathrm{C}$ and converted to an aerogel (WSA- 130C) as described above to study the effect of the surface area on digestibility. STMP-cross-linked aerogels (WSA-STMP) were formed by incorporating $1 \mathrm{wt} \%$ (starch basis) STMP into wheat starch dispersion (10 wt \%), followed by $\mathrm{SC}-\mathrm{CO}_{2}$ drying to form aerogels. Xerogels were generated by air drying of the alcogels at room temperature $\left(21^{\circ} \mathrm{C}\right)$ until a constant weight was achieved.

The samples were stored at room temperature $\left(21^{\circ} \mathrm{C}\right)$ until characterized. The surface area, pore size, pore volume, density, and porosity of the samples were determined according the methods described previously. ${ }^{6}$ Briefly, the Brunauer-Emmett-Teller (BET) surface area and Barrett-Joyner-Halenda (BJH) pore size and pore volume were determined from nitrogen adsorption-desorption isotherms measured at $-196{ }^{\circ} \mathrm{C}$ on a surface area and porosimetry system (ASAP 2020, Micromeritics Instrument Corporation, Norcross, GA, U.S.A.). Samples $(0.06-0.3 \mathrm{~g})$ were degassed at $115^{\circ} \mathrm{C}$ for $4 \mathrm{~h}$ under vacuum prior to analysis. The surface area was calculated using multipoint BET adsorption characteristics at a relative pressure between 0.05 and 0.3 , whereas pore size and volume were determined at a relative pressure 
of $>0.35$. Moreover, density of the samples was determined by measuring the dimensions of the monoliths and weighing them. The porosity was calculated using the bulk density $\left(\rho_{s}\right)$ of the samples and the true density $\left(\rho_{\mathrm{t}}=1.5 \mathrm{~g} \mathrm{~cm}^{-3}\right)$ of the starch using Equation $1 .{ }^{7}$

$$
\text { porosity }(\%)=\left(1-\frac{\rho_{s}}{\rho_{t}}\right) \times 100
$$

\section{Morphology}

The morphology of the samples (WSA-120C, WSA-130C, WSA-STMP, and xerogel) was examined using a field-emission scanning electron microscope (S4700 FE-SEM, Hitachi, Tokyo, Japan). ${ }^{7}$ Scanning electron microscopy (SEM) was operated in low-vacuum mode at $5 \mathrm{kV}$ and 15 $\mathrm{mA}$. The specimens were prepared by cutting $1 \mathrm{~mm}$ thick cross sections from the center of the monoliths using a double-edged razor blade. Then, the specimens were placed on double-side conductive carbon tape mounted onto circular aluminum SEM stubs. The samples were sputter-coated with a chromium layer under vacuum (Desk V HP TSC, Denton Vacuum LLC, Moorestown, NJ, U.S.A.) for 5 min prior to analysis. The thickness of the fibrils was calculated using ImageJ version 1.50i software [public domain, National Institutes of Health $(\mathrm{NIH})$, Bethesda, MD, U.S.A.] from the captured SEM images.

\section{Crystallinity}

X-ray diffraction (XRD) analysis was performed to study the crystallinity of the samples. ${ }^{7}$ XRD patterns of the samples were measured using a PANalytical Empyrean diffractometer (Empyrean, PANalytical B.V., Almelo, Netherlands). The instrument was equipped with PIXcel ${ }^{3 \mathrm{D}}$ detector and operated with one-dimensional (1D) detection at $45 \mathrm{kV}$ and $40 \mathrm{~mA}$. The samples were ground and sieved through mesh 20 ( $0.85 \mathrm{~mm}$ screen) prior to analysis. The powdered samples were placed on the sample holder and continuously scanned between $2^{\circ}$ and $40^{\circ}$

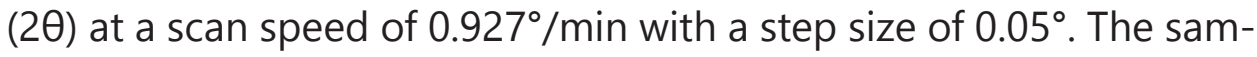
ple holder was spun at a rate of $3.75 \mathrm{rpm}$ throughout the analysis. Degree of crystallinity was calculated from the ratio of the area of the 
crystalline part to the total area of amorphous and crystalline parts using Software OriginPro 2017 (OriginLab Corporation, Northampton, MA, U.S.A.) ${ }^{6}$

\section{Fourier Transform Infrared Spectroscopy}

Attenuated total reflectance Fourier transform infrared (ATR-FTIR) spectra of the samples was determined using a Thermo Scientific Nicolet 380 spectrometer (Thermo Scientific, Waltham, MA, U.S.A.). The samples were scanned between 4000 and $400 \mathrm{~cm}^{-1}$. Each spectrum was collected by averaging 128 scans at a spectral resolution of $4 \mathrm{~cm}^{-1}$. Nicolet Omnic 8.3 software was used for deconvolution from 1200 to $800 \mathrm{~cm}^{-1}$ with a half bandwidth of $19 \mathrm{~cm}^{-1}$ and an enhancement factor of 1.9. ${ }^{19}$ The absorbance ratios at 1047/1022 and $1022 / 995 \mathrm{~cm}^{-1}$ were obtained from the deconvoluted spectra to estimate the short-range ordered structure of the samples.

Sample Preparation for Nuclear Magnetic Resonance (NMR) Analysis

WSA-STMP was digested prior to the ${ }^{31} \mathrm{P}$ NMR analysis using the method of Sang et al. ${ }^{11}$ Briefly, WSA-STMP was ground and sieved through a $0.85 \mathrm{~mm}$ screen (mesh 20). A total of $1 \mathrm{~g}$ of powdered WSA-STMP was digested with $100 \mu \mathrm{L}$ of heat-stable $\alpha$-amylase in 50 $\mathrm{mL}$ of $2.0 \mathrm{mM}$ calcium chloride. Digestion took place in a boiling water bath for $30 \mathrm{~min}$. Then, another $100 \mu \mathrm{L}$ of heat-stable $\alpha$-amylase was added, and the digestion was repeated. After $\alpha$-amylase digestion, the mixture was cooled and the $\mathrm{pH}$ was adjusted to 4.5. Then, the mixture was further digested with $200 \mu \mathrm{L}$ of amyloglucosidase at $60{ }^{\circ} \mathrm{C}$ for $1 \mathrm{~h}$. The mixture was adjusted to $\mathrm{pH} 7.0$ and centrifuged at $4000 \mathrm{~g}$ for $10 \mathrm{~min}$. Finally, the supernatant was freeze-dried for $24 \mathrm{~h}$ using a Freezone 6 freeze-dryer (Labconco, Kansas City, MO, U.S.A.).

${ }^{31}$ P NMR Spectra of the Digests of WSA-STMP

The freeze-dried digest of WSA-STMP (100 mg) was dissolved in 1 $\mathrm{mL}$ of deuterium oxide containing $20 \mathrm{mM}$ ethylenediaminetetraacetic acid (EDTA) and $0.002 \%$ sodium azide, and the solution was adjusted to $\mathrm{pH} 8.0$ with $0.1 \mathrm{M} \mathrm{NaOH}$. $\mathrm{KH}_{2} \mathrm{PO}_{4}$ was added as an internal 
standard to the solution. The proton-decoupled ${ }^{31} \mathrm{P}$ NMR spectra were acquired on a Bruker Avance III-HD $700 \mathrm{MHz}$ spectrometer equipped with a quadruple resonance $\mathrm{QCl}-\mathrm{P}$ cryoprobe $\left({ }^{1} \mathrm{H},{ }^{13} \mathrm{C},{ }^{15} \mathrm{~N}\right.$, and $\left.{ }^{31} \mathrm{P}\right)$. The system was operated at $700.17 \mathrm{MHz}$ for ${ }^{1} \mathrm{H}$ and $283.43 \mathrm{MHz}$ for ${ }^{31} \mathrm{P}$. The ${ }^{31} \mathrm{P}$ NMR spectra were collected with 128 scans using a recycle delay of $2.0 \mathrm{~s}$ and spectral width of $11.4 \mathrm{kHz}$. The spectra were recorded and analyzed with TopSpin 3.5 software.

\section{Viscosity}

The viscosities of the starch slurries were determined using a controlled-stress rheometer (Physica MCR 301, Anton Paar GmbH, Graz, Austria). The samples were prepared at the same concentration $(0.25$ $\mathrm{g} / 10 \mathrm{~mL}$ ) level used for the in vitro digestion. Parallel plates with a diameter of $50 \mathrm{~mm}$ (PP50) were used. The gap size was set to 1.00 $\mathrm{mm}$. At $5 \mathrm{~min}$ after the sample was loaded, a time sweep of $30 \mathrm{~min}$ at $37^{\circ} \mathrm{C}$ was performed at a constant shear rate of $200 \mathrm{~s}^{-1} .{ }^{20}$ Duplicate measurements were carried out for each sample.

\section{In Vitro Digestion}

WSAs and xerogel were ground and sieved through mesh $50(0.3 \mathrm{~mm}$ screen) and then subjected to in vitro digestion according to Mkandawire et al. ${ }^{21}$ In short, $250 \mathrm{mg}$ of starch sample was dispersed in 2 $\mathrm{mL}$ of water in a $15 \mathrm{~mL}$ test tube. Two treatments were applied before digestion, namely, cooked and uncooked. For the former treatment, the test tubes containing the samples were cooked in a boiling water bath for 20 min with vortex mixing several times during the first $5 \mathrm{~min}$ of cooking and then cooled by placing the tubes in a water bath at 37 ${ }^{\circ} \mathrm{C}$. For the latter treatment, the WSAs and xerogel were simply placed in the water bath at $37^{\circ} \mathrm{C}$. To achieve the gastric phase, $4 \mathrm{~mL}$ of $3.6 \%$ $(\mathrm{w} / \mathrm{v})$ pepsin in $50 \mathrm{mM}$ hydrochloric acid was added to each tube, vortex-mixed, and incubated for $30 \mathrm{~min}$ at $37^{\circ} \mathrm{C}$. Six glass beads $(6 \mathrm{~mm}$ diameter) were subsequently added to the tubes, followed by $2 \mathrm{~mL}$ of sodium acetate buffer $(0.5 \mathrm{M}, \mathrm{pH} 5.2$, containing $5 \mathrm{mM}$ calcium chloride). The small intestinal phase was initiated by adding $2.05 \mathrm{~mL}$ of an enzyme mixture. The enzyme mixture was prepared by adding pancreatin in water $(15 \%, w / v)$ on a magnetic stirrer for $10 \mathrm{~min}$ and then 
centrifuged for $10 \mathrm{~min}$ at $4000 \mathrm{~g}$. A total of $20 \mu \mathrm{L}$ of amyloglucosidase was added per milliliter of recovered pancreatin supernatant. Starch was digested over $2 \mathrm{~h}$ at $37^{\circ} \mathrm{C}$ with horizontal shaking at $200 \mathrm{rpm}$. A total of $50 \mu \mathrm{L}$ of aliquots of slurry was removed from the tube after exactly 20 and 120 min of digestion and mixed with $0.95 \mathrm{~mL}$ of absolute ethanol to stop the enzymatic reaction. The mixtures were then centrifuged at $5000 \mathrm{~g}$ for $5 \mathrm{~min}$. Glucose was quantified in the supernatant using the glucose oxidase-peroxidase method and was converted to starch content by multiplying by a factor of 0.9 . The starch that was converted to glucose within 20 min of digestion was rapidly digestible starch (RDS); the starch that was converted to glucose after 120 min of digestion was total digestible starch (TDS); and slowly digestible starch (SDS) was the fraction of starch digested between 20 and 120 min of in vitro digestion. RS was the fraction that remained undigested after 120 min under the experimental conditions and was obtained from the difference between total starch (TS) and TDS. A control digestion with cooked wheat starch was also performed.

\section{Statistical Analysis}

The results were expressed as the mean \pm standard deviation. Statistical analysis of the data was carried out using Minitab 16.1.1 software (Minitab, Inc., State Collage, PA, U.S.A.). Statistical differences among the treatments were determined by analysis of variance (ANOVA) and Tukey's multiple comparison test at a significance level of $p<0.05$.

\section{Results and Discussion}

WSA-120C was produced at the previously optimized aerogel formation conditions (temperature, mixing rate, and starch concentration during gelatinization and pressure, temperature, and flow rate of $\mathrm{CO}_{2}$ during $\mathrm{SC}-\mathrm{CO}_{2}$ drying) for the highest surface area. ${ }^{6}$ At the optimized conditions, WSA-120C had a surface area of $61 \mathrm{~m}^{2} / \mathrm{g}$, pore size of $18 \mathrm{~nm}$, pore volume of $0.27 \mathrm{~cm}^{3} / \mathrm{g}$, density of $0.11 \mathrm{~g} / \mathrm{cm}^{3}$, and porosity of $93 \%$ (Table 1). The surface area of WSA-130C (35 m²/g) was significantly lower compared to WSA-120C $(p<0.05)$, but its other textural properties were similar to that of WSA-120C (Table 1). Using STMP as a cross-linker decreased the pore volume and, consequently, 
Table 1. Textural Properties of the Aerogels and Xerogel ${ }^{a}$

\begin{tabular}{lrrrr} 
& WSA-120C & WSA-130C & WSA-STMP & xerogel \\
\hline BET surface area $\left(\mathrm{m}^{2} / \mathrm{g}\right)$ & $60.9 \pm 2.1 \mathrm{a}$ & $34.7 \pm 0.9 \mathrm{c}$ & $48.9 \pm 0.5 \mathrm{~b}$ & $0.04 \pm 0.00 \mathrm{~d}$ \\
BJH pore size $(\mathrm{nm})$ & $17.6 \pm 0.6 \mathrm{~b}$ & $25.1 \pm 0.9 \mathrm{~b}$ & $16.5 \pm 1.6 \mathrm{~b}$ & $267.9 \pm 8.7 \mathrm{a}$ \\
pore volume $\left(\mathrm{cm}^{3} / \mathrm{g}\right)$ & $0.27 \pm 0.01 \mathrm{a}$ & $0.17 \pm 0.01 \mathrm{~b}$ & $0.19 \pm 0.01 \mathrm{~b}$ & $0.002 \pm 0.000 \mathrm{c}$ \\
density $\left(\mathrm{g} / \mathrm{cm}^{3}\right)$ & $0.11 \pm 0.00 \mathrm{~b}$ & $0.10 \pm 0.00 \mathrm{~b}$ & $0.13 \pm 0.01 \mathrm{~b}$ & $0.41 \pm 0.03 \mathrm{a}$ \\
porosity $(\%)$ & $92.5 \pm 0.3 \mathrm{a}$ & $92.9 \pm 0.1 \mathrm{a}$ & $91.7 \pm 1.0 \mathrm{a}$ & $72.6 \pm 1.8 \mathrm{~b}$ \\
\hline
\end{tabular}

a. Data are means \pm standard deviations. Values in the same row with different letters are significantly different $(p<0.05)$.

the surface area of the aerogel compared to WSA-120C that was produced at the same processing conditions but without STMP. STMP was included in the wheat starch, aiming to produce aerogels with a more homogeneous fibrillar network structure and higher chemical stability. Air drying of the alcogels led to shrinkage of the porous structure of the alcogels as a result of high capillary forces during drying. Xerogels had a much lower surface area $\left(0.04 \mathrm{~m}^{2} / \mathrm{g}\right)$ with a few macropores $(268$ $\mathrm{nm})$, where the pore volume was almost zero $\left(0.002 \mathrm{~cm}^{3} / \mathrm{g}\right)$. Xerogels were also denser and less porous than the aerogel samples (Table 1).

\section{Morphology}

SEM images of WSA-120C, WSA-130C, WSA-STMP, and xerogel are depicted in Figure 1. All aerogels had an open porous network structure. WSA-120C (Figure 1a1) consisted of thinner fibrils compared to
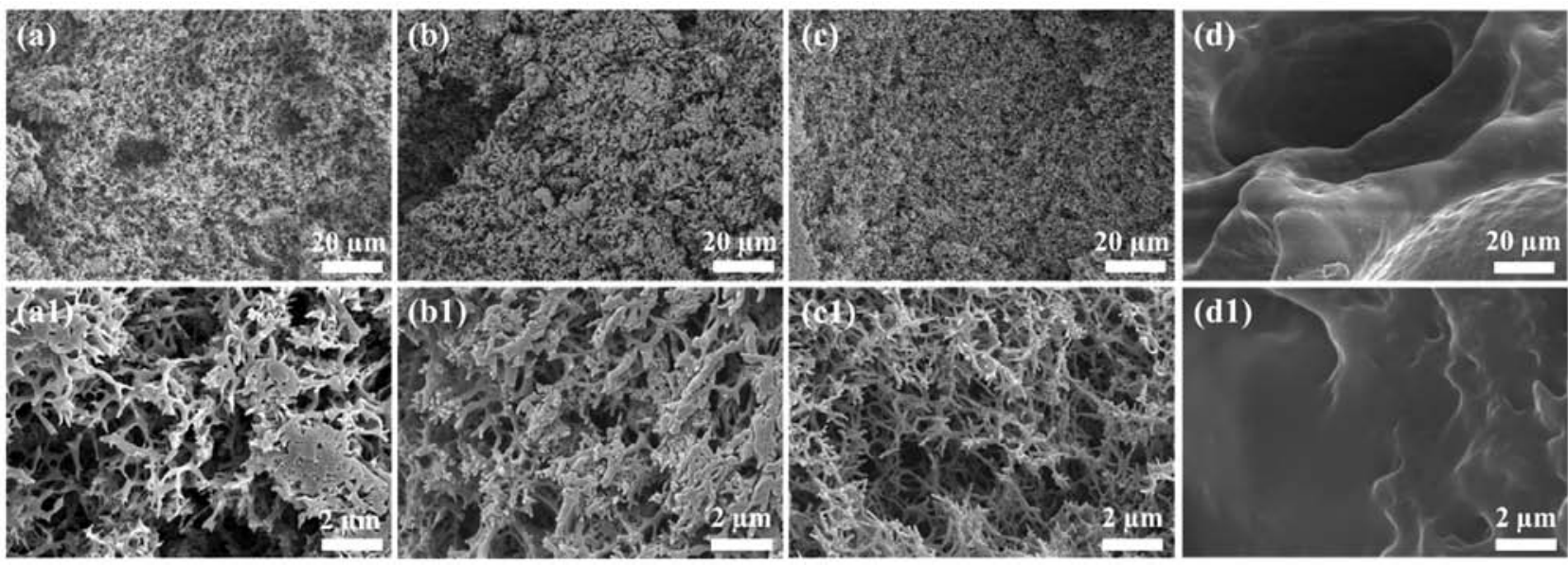

Figure 1. Low- and high-magnification SEM micrographs of WSAs [(a and a1) WSA120C, (b and b1) WSA-130C, and (c and c1) WSA-STMP] and ( $d$ and d1) xerogel. 
WSA-130C (Figure 1b1). The thicknesses of the fibrils were $205 \pm 42$ and $270 \pm 66 \mathrm{~nm}$ for WSA-120C and WSA-130C, respectively. Those results were consistent with our previous study. ${ }^{6}$ Higher thickness of the fibrillar structure of WSA-130C resulted in a lower surface area (Table 1), which could be due to bursting of swollen starch granules at that high temperature. ${ }^{22}$ On the other hand, WSA-STMP showed a more homogeneous fibrillar structure compared to the other aerogels (Figure 1c1). The thickness of the interconnected fibrils in WSASTMP was $129 \pm 21 \mathrm{~nm}$. The porous structure of the alcogel collapsed during air drying as a result of high surface tension in the pores, and therefore, a non-porous material was obtained (panels $d$ and $d 1$ of Figure 1).

\section{Crystallinity}

Wheat starch exhibited an A-type crystalline structure with strong diffraction peaks at $2 \theta=14.9^{\circ}, 16.9^{\circ}, 17.8^{\circ}$, and $22.9^{\circ}$ (Figure 2). Those typical diffraction peaks from A-type crystallites almost disappeared, indicating the complete gelatinization as the heating temperature was $120^{\circ} \mathrm{C}$. were mainly attributed to the amylose-lipid complexes and retrograded B-type crystallites. The crystallinity of wheat starch (21.3\%) was consistent with the literature. ${ }^{23}$ WSA-120C, WSA-130C, WSA-STMP, and xerogel showed similar relative crystallinities as 6.2, $5.9,6.1$, and 6.5 , respectively $(p>0.05)$, which was expected as a result

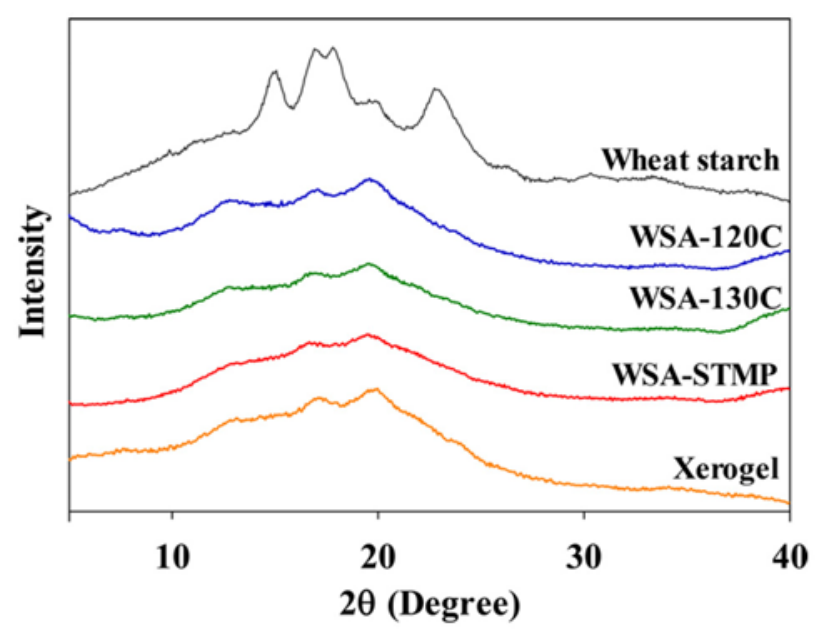

Figure 2. XRD patterns of wheat starch, WSAs (WSA-120C, WSA-130C, and WSASTMP), and xerogel. 
Table 2. Crystallinity and Short-Range Molecular Order of the Samples ${ }^{a}$

\begin{tabular}{lcrcr} 
sample & $\begin{array}{c}X R D \text { total } \\
\text { crystallinity (\%) }\end{array}$ & $\begin{array}{c}\text { XRD crystallinity (\%) } \\
\text { at } 2 \theta=13^{\circ} \text { and } 20^{\circ}\end{array}$ & $\begin{array}{c}\text { FTIR 1047/1022 } \\
\text { ratio }\end{array}$ & \multicolumn{1}{c}{$\begin{array}{c}\text { FTIR 1022/995 } \\
\text { ratio }\end{array}$} \\
\hline wheat starch & $21.31 \pm 0.39 \mathrm{a}$ & $1.01 \pm 0.07 \mathrm{e}$ & $0.660 \pm 0.004 \mathrm{a}$ & $0.758 \pm 0.023 \mathrm{~b}$ \\
WSA-120C & $6.19 \pm 0.35 \mathrm{~b}$ & $3.92 \pm 0.01 \mathrm{a}$ & $0.422 \pm 0.004 \mathrm{c}$ & $0.845 \pm 0.041 \mathrm{ab}$ \\
WSA-130C & $5.92 \pm 0.26 \mathrm{~b}$ & $3.35 \pm 0.01 \mathrm{~b}$ & $0.428 \pm 0.001 \mathrm{c}$ & $0.848 \pm 0.042 \mathrm{ab}$ \\
WSA-STMP & $6.08 \pm 0.29 \mathrm{~b}$ & $1.86 \pm 0.04 \mathrm{~d}$ & $0.431 \pm 0.001 \mathrm{c}$ & $0.903 \pm 0.045 \mathrm{a}$ \\
xerogel & $6.47 \pm 0.12 \mathrm{~b}$ & $2.91 \pm 0.04 \mathrm{c}$ & $0.527 \pm 0.009 \mathrm{~b}$ & $0.845 \pm 0.010 \mathrm{ab}$ \\
\hline
\end{tabular}

a. Data are means \pm standard deviations. Values in the same column with different letters are significantly different $(p<0.05)$.

of the gelatinization step during the production of all of those samples. Both diffraction peaks at $2 \theta=13^{\circ}$ and $20^{\circ}$ indicate the formation of the amylose-lipid complex.9,24 Although there was no notable difference between the total relative crystallinity among the aerogel and xerogel samples, the percent degree of crystallinity resulting from amylose-lipid complexation was significantly different ( $p$ 0.05) (Table 2). The degree of crystallinity resulting from the amylose-lipid complex formation in wheat starch was 1.0\%, which agreed with the findings of Chen et al. ${ }^{9}$ The highest amylose-lipid complex formation was obtained with WSA-120C, corresponding to 3.9\% relative crystallinity $(p<0.05)$. Although the percent degree of crystallinity resulting from amylose-lipid complexation varied in a narrow range of 1 and 3.9\%, we speculate that the small change in the amylose-lipid complexation amount can make a huge difference on the physical properties and, consequently, affect the digestibility. To illustrate, the increase in the percent degree of crystallinity resulting from amylose-lipid complexation from 0.58 to $2.02 \%$ influenced the crystalline structure and digestibility of wheat starch. ${ }^{9}$ STMP addition resulted in the lowest amylose-lipid complexation among the gels. STMP may have interfered with the molecular structure of amylose-lipid complex formation and disrupted the complexation. Similar findings were obtained in previous studies, ${ }^{11,25}$ where cross-linking of wheat starch with STMP prevented the formation of the amylose-lipid complex. The differences in amylose-lipid complex formation may be relevant to starch digestibility, because the amylose- lipid complex produces RS as a result of the entrapment of the hydrophobic fatty acid tail inside of the amylose helix, which restricts the ability of digestive enzymes to break down starch. ${ }^{10,26}$ 


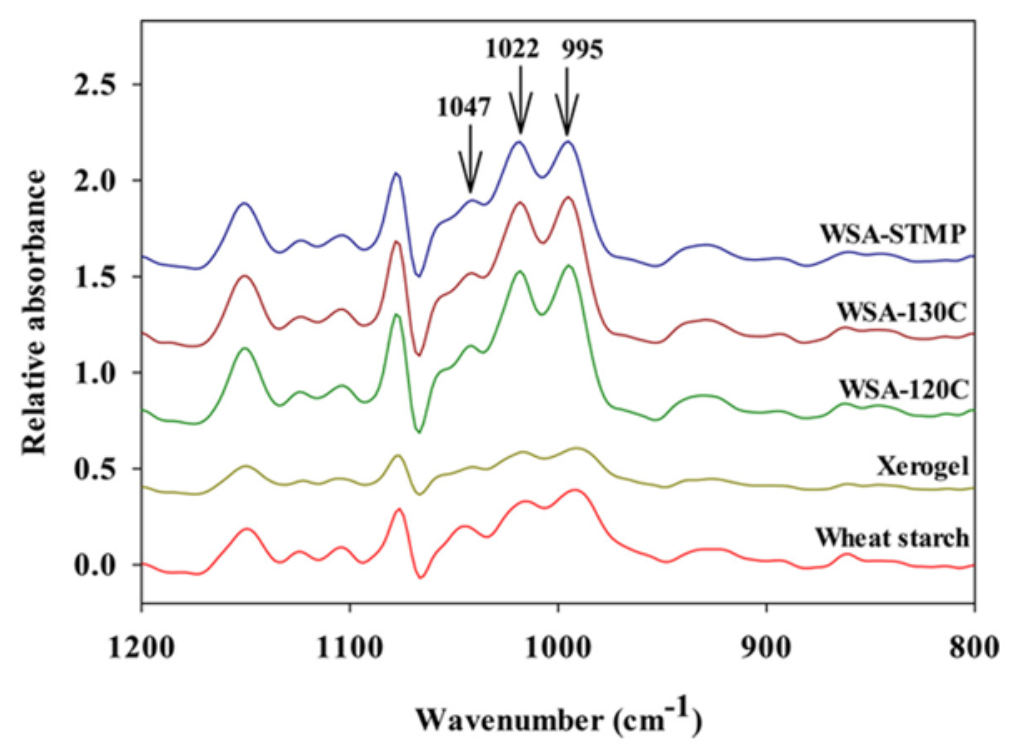

Figure 3. Deconvoluted ATR-FTIR spectra of WSA-STMP, WSA- 130C, WSA-120C, xerogel, and wheat starch.

\section{ATR-FTIR Spectroscopy}

All of the ATR-FTIR spectra of the samples were similar (data not shown); therefore, only the deconvoluted ATR-FTIR spectra of the samples in the range of $1200-800 \mathrm{~cm}^{-1}$ are presented in Figure 3. The intensity of the FTIR bands at 1047, 1022, and $995 \mathrm{~cm}^{-1}$ were determined, and then the absorbance ratios at 1047/1022 and 1022/995 $\mathrm{cm}^{-1}$ were calculated (Table 2). The ATR-FTIR spectrum of starch is known to be sensitive to the changes in short-range molecular order of starch, especially in the range of $1200-800 \mathrm{~cm}^{-1}$, where $\mathrm{C}-\mathrm{O}-\mathrm{H}$ bending vibrations and $\mathrm{C}-\mathrm{C}$ and $\mathrm{C}-\mathrm{O}$ stretching vibrations are observed. ${ }^{17,27} \mathrm{~A}$ higher absorbance ratio at $1047 / 1022 \mathrm{~cm}^{-1}$ indicates higher total relative crystallinity because the ATR-FTIR bands at 1047 and $1022 \mathrm{~cm}^{-1}$ are associated with the crystalline and amorphous parts of the starch structure, respectively. ${ }^{28,29}$ ATR-FTIR absorbance ratios of the samples at $1047 / 1022 \mathrm{~cm}^{-1}$ are given in Table 2 . The results were in agreement with the XRD total relative crystallinity data, meaning that gelatinization disrupted not only the long-range crystallites but also the short-range molecular order of wheat starch. However, xerogel had a significantly higher absorbance ratio at 1047/1022 $\mathrm{cm}^{-1}$ compared to the WSAs (Table 2), which can be explained by the drying procedure. Xerogels were obtained with air drying at room 
temperature $\left(21^{\circ} \mathrm{C}\right)$ overnight. On the other hand, aerogels were collected after $4 \mathrm{~h}$ of $\mathrm{SC}-\mathrm{CO}_{2}$ drying at $40^{\circ} \mathrm{C}$ and $10 \mathrm{MPa}$. It can be speculated that the drying method of the xerogels allowed for the formation of a more ordered molecular structure and resulted in higher crystallinity. Furthermore, the ATR-FTIR absorbance ratio at 1022/995 $\mathrm{cm}^{-1}$ was calculated because it shows the state of organization of the double helices inside crystallites. ${ }^{30} \mathrm{~A}$ higher ratio of absorbance at $1022 / 995 \mathrm{~cm}^{-1}$ indicates lower molecular order of double helices. ${ }^{19}$ The absorbance ratios at 1022/995 $\mathrm{cm}^{-1}$ were similar for all of the gels; however, WSA-STMP exhibited a significantly higher absorbance ratio at 1022/995 $\mathrm{cm}^{-1}$ than wheat starch (Table 2) as a result of the effect of phosphates on the structure of helices.

\section{${ }^{31}$ P NMR Spectroscopy}

${ }^{31} \mathrm{P}$ NMR analysis was conducted to determine the location of phosphate esters and their concentration in WSA-STMP. The ${ }^{31} \mathrm{P}$ NMR spectrum of water-soluble $\alpha$-limit dextrins and phosphate compounds is depicted in Figure 4. The results indicated that wheat starch was cross-linked with phosphate to form distarch monophosphate (DSMP),

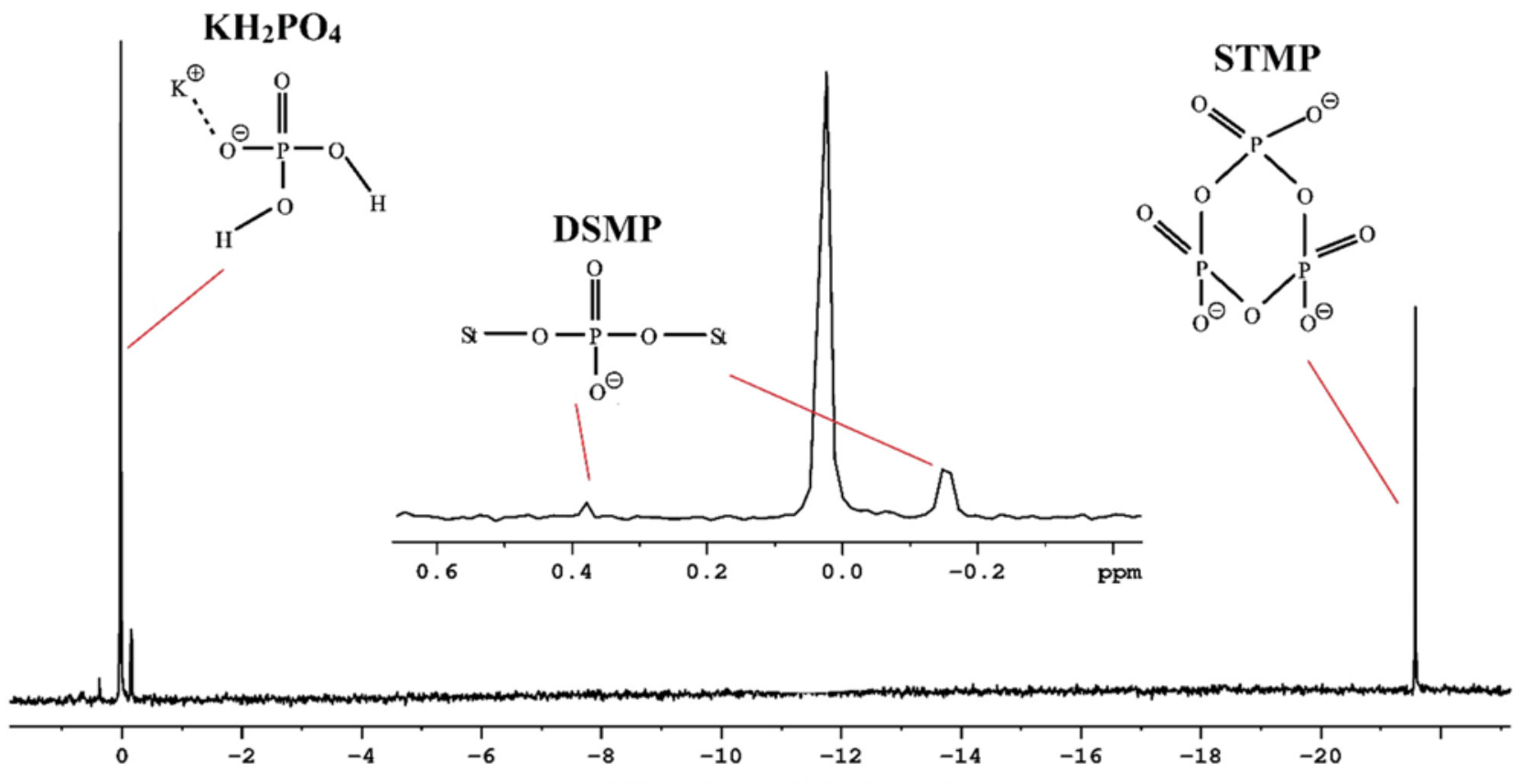

Chemical shift (ppm)

Figure 4. ${ }^{31} \mathrm{P}$ NMR spectrum of $\alpha$-amylase/amyloglucosidase digest of WSA-STMP. 
which was the only phosphate ester type in WSA-STMP.25 ${ }^{31} \mathrm{P}$ NMR signals at $\delta 0.38,0.02,-0.15$, and $-21.57 \mathrm{ppm}$ were corresponding to DSMP, $\mathrm{KH}_{2} \mathrm{PO}_{4}$, DSMP, and unreacted STMP, respectively. Similar ${ }^{31} \mathrm{P}$ NMR chemical shifts of phosphodextrins and phosphorus compounds were reported in previous studies. ${ }^{11,25,31}$ Manoi and Rizvi ${ }^{25}$ found that the signals at $\delta 0.38$ and $-0.15 \mathrm{ppm}$ corresponded to covalently bound monophosphate to $\mathrm{C} 6$ and $\mathrm{C} 3$ positions of glucose residues in starch, respectively. The C6-monophosphate ester was the dominant form when wheat starch was phosphorylated..$^{25}$ Similarly, the proportion of phosphate bound to the C6 position of glucose was higher than that of phosphate bound to the $\mathrm{C} 3$ position because the intensity of the peak at $\delta-0.15$ ppm was higher (Figure 4). Moreover, the hydroxyl groups on both the C6 and C3 positions of glucose units are located on the surface of the double helix. ${ }^{32}$ Binding of phosphate groups to those positions of the glucose units might affect the structure and stability of the double helices, which can be the reason for having lower molecular order of double helices with the addition of STMP, as studied by the ATR-FTIR absorbance ratio at 1022/995 $\mathrm{cm}^{-1}$ (Table 2).

The phosphorus content in DSMP was calculated from ${ }^{31} \mathrm{P}$ NMR data by integration of the peaks at $\delta 0.38$ and $-0.15 \mathrm{ppm}$. The signal at $\delta 0.02 \mathrm{ppm}$, which corresponded to $\mathrm{KH}_{2} \mathrm{PO}_{4}$ and did not interfere with the other peaks, was used as the internal standard (Figure 4). The amount of incorporated phosphorus in WSA-STMP was very low as $0.023 \mathrm{wt} \%$, which was expected because the gelatinization conditions ( $\mathrm{pH} \sim 7$ and $10 \mathrm{wt} \%$ starch concentration) were not in favor of chemical cross-linking. For an effective crosslinking of wheat starch by phosphorylation, an alkaline slurry $(\mathrm{pH} \sim 11)$ of wheat starch ( 30 wt \%) with STMP is required..$^{11,33}$ Although only a small portion of STMP reacted with wheat starch, the microstructure and the surface area were significantly affected (Table 1 and Figure 1). Furthermore, DSMP cross-links may provide paste stability against high temperature, low $\mathrm{pH}$, and high shear. ${ }^{11}$ Cross-linking is also known to decrease the digestibility of wheat starch by reducing the activity of amylolytic enzymes via limiting the entrance of $\alpha$-amylase through porous channels or interfering with $\alpha$ - amylase and starch complex formation. ${ }^{34}$ 
Viscosity

Viscosity of the starch matrix affects not only the food processing steps but also the enzymatic digestibility of starch. 35,36 High viscosity may influence the diffusion of substrates, availability of water required for hydrolysis, and accessibility of the enzymes to starch. ${ }^{37} \mathrm{Al}-$ though the viscosity of starch samples changes throughout digestion as a result of hydrolysis, the viscosity of the starting material provides useful information for the digestion rate and further food applications of WSAs. Figure 5 depicts the apparent viscosity of wheat starch, WSA-120C, WSA-130C, WSA-STMP, and xerogel slurries at 37 ${ }^{\circ} \mathrm{C}$ under a constant shear rate of $200 \mathrm{~s}^{-1}$. Viscosity measurement conditions $\left(37^{\circ} \mathrm{C}\right.$ and $\left.200 \mathrm{~s}^{-1}\right)$ were selected on the basis of our in vitro digestion methodology. The xerogel slurry revealed the highest viscosity because air drying formed a very rigid structure with the highest density (Table 1). The viscosities of WSA-120C and WSA-STMP were similar because they were produced using the same processing temperature $\left(120^{\circ} \mathrm{C}\right)$ during the gelatinization step. The addition of STMP did not influence the viscosity as a result of the low degree of cross-linking. The viscosity of WSA slurries increased with increasing the processing temperature from 120 to $130{ }^{\circ} \mathrm{C}$ during the formation of WSAs. ${ }^{38}$ Furthermore, gelatinized wheat starch samples had much

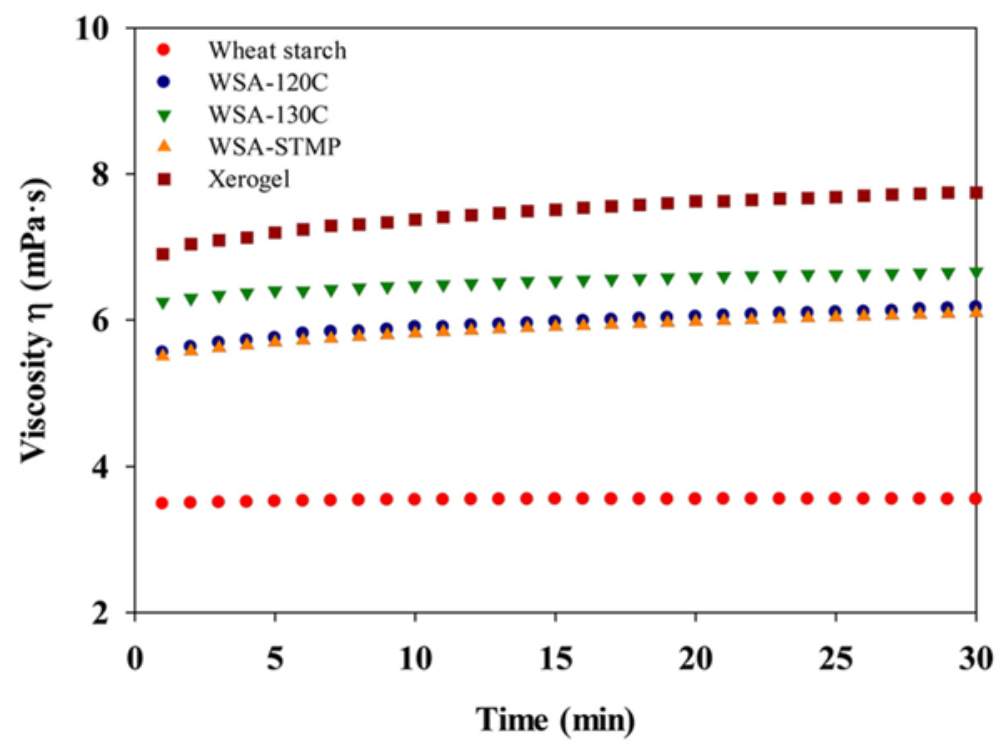

Figure 5. Time sweep profiles of viscosity of the samples at $37^{\circ} \mathrm{C}$ and $200 \mathrm{~s}^{-1}$. 
lower crystallinity than the wheat starch, which increased their water solubility ${ }^{6}$ and water uptake. ${ }^{39}$ Therefore, wheat starch revealed lower apparent viscosity compared to other samples (Figure 5).

\section{In Vitro Digestibility}

The in vitro digestibility of starch samples without any cooking step prior to digestion is presented in Table 3. WSA-STMP and xerogel exhibited higher RS contents as 34 and 27\%, respectively. The RS content of WSA-120C (13\%) was significantly lower than those of WSASTMP and xerogel samples, while WSA-120C showed a similar RS content to WSA-130C (17\%) (Table 3). The variation in the surface area of the aerogels $\left(61 \mathrm{~m}^{2} / \mathrm{g}\right.$ for WSA-120C versus $35 \mathrm{~m}^{2} / \mathrm{g}$ for WSA130C) did not have a significant effect on the RDS, SDS, and RS contents of WSA-120C and WSA-130C, which could be due to the similar density, porosity, and total relative crystallinity of those samples. There were no significant differences in the SDS content of the samples. Nevertheless, the RDS content of WSA-STMP was significantly lower than those of the other samples, which may contribute to lowering the glycemic index..$^{40}$

Xerogels exhibited higher short-range molecular order, as studied by the ATR-FTIR absorbance ratio at 1047/1022 $\mathrm{cm}^{-1}$, and they had higher density and viscosity with a lower surface area compared to the other samples. These properties may have limited the accessibility of the digestion enzymes to the xerogels and resulted in a higher RS content. Similarly, the increase in the crystallinity of the wheat starches limited the starch digestibility in a previous study. ${ }^{41}$

Table 3. In Vitro Digestibility of Starch Samples (Uncooked Prior to Digestion) ${ }^{a}$

\begin{tabular}{lccr} 
& \multicolumn{3}{c}{ starch digestibility (\%, db) } \\
sample & RDS & SDS & $R S$ \\
\hline WSA-120C & $65.0 \pm 1.3 \mathrm{a}$ & $21.8 \pm 3.5 \mathrm{a}$ & $13.2 \pm 4.9 \mathrm{c}$ \\
WSA-130C & $57.0 \pm 2.9 \mathrm{a}$ & $26.0 \pm 5.6 \mathrm{a}$ & $17.0 \pm 2.7 \mathrm{bc}$ \\
WSA-STMP & $45.2 \pm 3.5 \mathrm{~b}$ & $21.3 \pm 3.5 \mathrm{a}$ & $33.5 \pm 0.1 \mathrm{a}$ \\
xerogel & $57.5 \pm 1.2 \mathrm{a}$ & $15.6 \pm 1.4 \mathrm{a}$ & $26.9 \pm 2.7 \mathrm{ab}$ \\
\hline
\end{tabular}

a. Data are means \pm standard deviations. Values in the same column with different letters are significantly different $(p<0.05)$. 
The WSA-STMP aerogel also showed relatively high RS. Chemical cross-linking obtained by the addition of STMP limited the starch digestion by $\alpha$-amylase and, consequently, produced a higher RS fraction. To illustrate, the phosphorylated wheat starch $(0.37 \mathrm{wt} \%$ phosphorus content) had a RS content of $69 \%,{ }^{11}$ which had a much higher level of phosphorus content compared to that obtained in this study (0.023 wt \%).

The digestibility values in Table 3 reveal fundamental information for the applications of the aerogels where no cooking pretreatment is required; however, for some food applications, WSAs may be recooked. Therefore, the digestibility of the samples was also determined after a cooking step for 20 min in a boiling water bath (Table 4). Wheat starch was studied as a control and showed a RS content of $3.2 \%$. The RS content was improved up to 4.5-fold with WSA-130C compared to the wheat starch. Cooking decreased the RS contents of WSA-STMP and xerogel by 83.9 and $88.1 \%$, respectively. Nevertheless, the RS contents of WSA-120C and WSA-130C were less affected by cooking because the decrease in RS contents were only 26.5 and $15.9 \%$, respectively (Table 4 ). Amylose-lipid complexes played a significant role in the decrease of the RS contents of the samples after the cooking step. The dissociation temperature of the crystalline amylose - lipid complexes is above $100{ }^{\circ} \mathrm{C}_{i}^{42}$ consequently, those crystallites were more stable upon cooking. Moreover, amylose-lipid complexes retard swelling during cooking, which reduces the enzyme ability to hydrolyze the starch. ${ }^{42}$ The amylose-lipid complex contents

Table 4. In Vitro Digestibility of Starch Samples (Cooked Prior to Digestion) ${ }^{a}$

\begin{tabular}{|c|c|c|c|c|}
\hline \multirow[b]{2}{*}{ sample } & \multicolumn{3}{|c|}{ starch digestibility $(\%, \mathrm{db})$} & \multirow{2}{*}{$\begin{array}{r}\text { decrease in RS } \\
\text { content }(\%)^{\mathrm{b}}\end{array}$} \\
\hline & RDS & SDS & RS & \\
\hline wheat starch & $79.6 \pm 3.1 \mathrm{a}$ & $17.2 \pm 3.8 a$ & $3.2 \pm 0.7 b$ & $N^{c}$ \\
\hline WSA-120C & $85.4 \pm 4.2 \mathrm{a}$ & $4.9 \pm 2.2 b$ & $9.7 \pm 2.0 \mathrm{ab}$ & 26.5 \\
\hline WSA-130C & $79.8 \pm 5.4 \mathrm{a}$ & $5.9 \pm 1.9 b$ & $14.3 \pm 3.5 a$ & 15.9 \\
\hline WSA-STMP & $89.7 \pm 2.0 a$ & $4.9 \pm 0.2 b$ & $5.4 \pm 2.2 b$ & 83.9 \\
\hline xerogel & $87.8 \pm 1.5 \mathrm{a}$ & $9.0 \pm 0.3 a b$ & $3.2 \pm 1.2 b$ & 88.1 \\
\hline
\end{tabular}

a. Data are means \pm standard deviations. Values in the same column with different letters are significantly different $(p<0.05)$.

b. The percent decrease in the RS content after cooking was calculated as (RS content without cooking - RS content with cooking)/RS content without cooking $\times 100$.

c. Not applicable. 
of xerogel and WSASTMP were lower than those of WSA-120C and WSA-130C (Table 2). Therefore, the RS contents of WSA-120C and WSA-130C were decreased to a lesser extent compared to other samples after the cooking treatment. On the other hand, the WSA-STMP structure was not stable upon cooking treatment because of the low degree of chemical cross-linking (phosphorylation) ${ }^{37,43}$ and STMP interfering with the crystalline amylose-lipid complex formation, as mentioned above.

WSA-120C demonstrated a slightly lower RS fraction than WSA$130 \mathrm{C}$ in both with and without cooking pretreatment. Having a higher surface area with WSA-120C might have enhanced the $\alpha$-amylase accessibility to the starch matrix. Moreover, processing the starch dispersion at a high temperature $\left(130{ }^{\circ} \mathrm{C}\right)$ produced extremely stable $\mathrm{RS} ; i^{15}$ therefore, the change in the RS content was minimized in this sample. Similar to our gelatinization process, a high-pressure autoclaving process produced an enzyme-resistant fraction in wheat starch. ${ }^{44}$ Cooked aerogel samples could lead to a burst release of the loaded bioactives in the first 20 min of the digestion. On the other hand, cooked starch aerogels still have a higher RS content compared to wheat starch; consequently, the incorporation of those samples into foods will increase the RS content, which is known to exert several health benefits, such as reducing the risk of developing colon cancer and cardiovascular diseases. ${ }^{15}$

In conclusion, food-grade WSAs were successfully fabricated using $\mathrm{SC}-\mathrm{CO}_{2}$ technology. WSAs had outstanding properties, such as a surface area of $61 \mathrm{~m}^{2} / \mathrm{g}$, pore size of $18 \mathrm{~nm}$, and density of $0.11 \mathrm{~g} /$ $\mathrm{cm}^{3}$. All WSAs exhibited a three-dimensional porous network structure. Although the total relative crystallinity of the WSAs was similar, the highest amount of amylose-lipid complexation contributing to the total crystallinity was achieved with WSA-120C. The addition of STMP interfered with the amylose-lipid complex formation and the structure of double helices. Xerogel showed the highest apparent viscosity. Using STMP as a chemical cross-linker decreased the digestibility of WSAs when the digestibility was tested without a cooking pretreatment. Therefore, RS contents of WSA-STMP and xerogel were maximized when they were uncooked prior to digestion. However, the structures of those samples were not stable with cooking, which led to a drastic decrease in the RS fractions after cooking. WSA-120C and WSA-130C preserved their structure during cooking and resulted in 
higher RS contents. Nevertheless, the surface area of the WSAs did not create a significant impact on their digestibility. This study introduces for the first time the digestibility of the starch aerogels, which is relevant to the efficacy of the aerogels in both food and pharmaceutical applications. WSAs will increase the RS content when incorporated into food products. Moreover, the addition of WSAs have the potential to decrease the caloric value of the foods as a result of their ultralow density and high porosity.

Funding - This project is based on research that was partially supported by the $\mathrm{Ne}$ braska Agricultural Experiment Station with funding from the Hatch Multistate Research Capacity Funding Program (Accession 1011129) from the United States Department of Agriculture (USDA) National Institute of Food and Agriculture, Nebraska Research Initiative, and Agricultural Research Division (ARD) Innovation Fund for Wheat/Cereal Crops and the Wheat/Cereal Scholarship \& Fellowship Support Fund.

Notes - The authors declare no competing financial interest.

\section{References}

(1) Ulker, Z.; Erkey, C. An emerging platform for drug delivery: Aerogel based systems. J. Controlled Release 2014, 177, 51-63.

(2) Stergar, J.; Maver, U. Review of aerogel-based materials in biomedical applications. J. Sol-Gel Sci. Technol. 2016, 77 (3), 738- 752.

(3) Pantić, M.; Knez, Ž.; Novak, Z. Supercritical impregnation as a feasible technique for entrapment of fat-soluble vitamins into alginate aerogels. J. Non-Cryst. Solids 2016, 432 (Part B), 519-526.

(4) Smirnova, I.; Gurikov, P. Aerogels in chemical engineering: Strategies toward tailor-made aerogels. Annu. Rev. Chem. Biomol. Eng. 2017, 8 (1), 307-334.

(5) García-González, C. A.; Jin, M.; Gerth, J.; Alvarez-Lorenzo, C.; Smirnova, I. Polysaccharide-based aerogel microspheres for oral drug delivery. Carbohydr. Polym. 2015, 117, 797-806.

(6) Ubeyitogullari, A.; Ciftci, O. N. Formation of nanoporous aerogels from wheat starch. Carbohydr. Polym. 2016, 147, 125-132.

(7) Ubeyitogullari, A.; Ciftci, O. N. Phytosterol nanoparticles with reduced crystallinity generated using nanoporous starch aerogels. RSC Adv. 2016, 6 (110), 108319-108327.

(8) Ubeyitogullari, A.; Ciftci, O. N. Generating phytosterol nanoparticles in nanoporous bioaerogels via supercritical carbon dioxide impregnation: Effect of impregnation conditions. J. Food Eng. 2017, 207, 99-107. 
(9) Chen, X.; He, X.; Fu, X.; Huang, Q. In vitro digestion and physicochemical properties of wheat starch/flour modified by heat-moisture treatment. J. Cereal Sci. 2015, 63, 109-115.

(10) Dupuis, J. H.; Liu, Q.; Yada, R. Y. Methodologies for increasing the resistant starch content of food starches: A review. Compr. Rev. Food Sci. Food Saf. 2014, 13 (6), 1219-1234.

(11) Sang, Y.; Seib, P. A.; Herrera, A. I.; Prakash, O.; Shi, Y.-C. Effects of alkaline treatment on the structure of phosphorylated wheat starch and its digestibility. Food Chem. 2010, 118 (2), 323-327.

(12) Li, W.; Tian, X.; Wang, P.; Saleh, A. S. M.; Luo, Q.; Zheng, J.; Ouyang, S.; Zhang, G. Recrystallization characteristics of high hydrostatic pressure gelatinized normal and waxy corn starch. Int. J. Biol. Macromol. 2016, 83, 171-177.

(13) Shu, X.; Backes, G.; Rasmussen, S. K. Genome-wide association study of resistant starch (RS) phenotypes in a barley variety collection. J. Agric. Food Chem. 2012, 60 (41), 10302-10311.

(14) Birt, D. F.; Boylston, T.; Hendrich, S.; Jane, J.-L.; Hollis, J.; Li, L.; McClelland, J.; Moore, S.; Phillips, G. J.; Rowling, M.; Schalinske, K.; Scott, M. P.; Whitley, E. M. Resistant starch: Promise for improving human health. Adv. Nutr. 2013, 4 (6), 587-601.

(15) Sajilata, M. G.; Singhal, R. S.; Kulkarni, P. R. Resistant starch-a review. Compr. Rev. Food Sci. Food Saf. 2006, 5 (1), 1-17.

(16) Zeng, H.; Huang, C.; Lin, S.; Zheng, M.; Chen, C.; Zheng, B.; Zhang, Y. Lotus seed resistant starch regulates gut microbiota and increases short-chain fatty acids production and mineral absorption in mice. J. Agric. Food Chem. 2017, 65 (42), 9217-9225.

(17) Wang, S.; Luo, H.; Zhang, J.; Zhang, Y.; He, Z.; Wang, S. Alkali-induced changes in functional properties and in vitro digestibility of wheat starch: The role of surface proteins and lipids. J. Agric. Food Chem. 2014, 62 (16), 3636-3643.

(18) Gao, F.; Li, D.; Bi, C.-h.; Mao, Z.-h.; Adhikari, B. Preparation and characterization of starch crosslinked with sodium trimetaphosphate and hydrolyzed by enzymes. Carbohydr. Polym. 2014, 103, 310-318.

(19) Wang, S.; Wang, S.; Liu, L.; Wang, S.; Copeland, L. Structural orders of wheat starch do not determine the in vitro enzymatic digestibility. J. Agric. Food Chem. 2017, 65 (8), 1697-1706.

(20) Tamura, M.; Singh, J.; Kaur, L.; Ogawa, Y. Impact of the degree of cooking on starch digestibility of rice-An in vitro study. Food Chem. 2016, 191, 98-104.

(21) Mkandawire, N. L.; Kaufman, R. C.; Bean, S. R.; Weller, C. L.; Jackson, D. S.; Rose, D. J. Effects of sorghum (Sorghum bicolor (L.) Moench) tannins on $\alpha$-amylase activity and in vitro digestibility of starch in raw and processed flours. J. Agric. Food Chem. 2013, 61 (18), 4448-4454.

(22) Glenn, G. M.; Klamczynski, A.; Chiou, B. S.; Orts, W. J.; Imam, S. H.; Wood, D. F. Temperature related structural changes in wheat and corn starch granules and their effects on gels and dry foam. Starch/Staerke 2008, 60, 476-484.

(23) Ratnayake, W. S.; Jackson, D. S. A new insight into the gelatinization process of native starches. Carbohydr. Polym. 2007, 67, 511-529. 
(24) Shah, A.; Masoodi, F. A.; Gani, A.; Ashwar, B. A. In-vitro digestibility, rheology, structure, and functionality of RS3 from oat starch. Food Chem. 2016, 212, 749-758.

(25) Manoi, K.; Rizvi, S. S. H. Physicochemical characteristics of phosphorylated cross-linked starch produced by reactive supercritical fluid extrusion. Carbohydr. Polym. 2010, 81 (3), 687-694.

(26) Chanvrier, H.; Uthayakumaran, S.; Appelqvist, I. A. M.; Gidley, M. J.; Gilbert, E. P.; López-Rubio, A. Influence of storage conditions on the structure, thermal behavior, and formation of enzyme-resistant starch in extruded starches. J. Agric. Food Chem. 2007, 55 (24), 9883- 9890.

(27) Wang, S.; Li, C.; Zhang, X.; Copeland, L.; Wang, S. Retrogradation enthalpy does not always reflect the retrogradation behavior of gelatinized starch. Sci. Rep. 2016, 6, 20965.

(28) Wang, S.; Wang, J.; Zhang, W.; Li, C.; Yu, J.; Wang, S. Molecular order and functional properties of starches from three waxy wheat varieties grown in China. Food Chem. 2015, 181, 43-50.

(29) Sevenou, O.; Hill, S. E.; Farhat, I. A.; Mitchell, J. R. Organisation of the external region of the starch granule as determined by infrared spectroscopy. Int. J. Biol. Macromol. 2002, 31 (1), 79-85.

(30) Ambigaipalan, P.; Hoover, R.; Donner, E.; Liu, Q. Retrogradation characteristics of pulse starches. Food Res. Int. 2013, 54 (1), 203-212.

(31) Sang, Y.; Prakash, O.; Seib, P. A. Characterization of phosphorylated crosslinked resistant starch by 31P nuclear magnetic resonance (31P NMR) spectroscopy. Carbohydr. Polym. 2007, 67 (2), 201-212.

(32) Blennow, A.; Nielsen, T. H.; Baunsgaard, L.; Mikkelsen, R.; Engelsen, S. B. Starch phosphorylation: A new front line in starch research. Trends Plant Sci. 2002, 7 (10), 445-450.

(33) Woo, K.; Seib, P. a. Cross-linking of wheat starch and hydroxypropylated wheat starch in alkaline slurry with sodium trimetaphosphate. Carbohydr. Polym. 1997, 33 (4), 263-271.

(34) Woo, K. S.; Seib, P. A. Cross-linked resistant starch: Preparation and properties. Cereal Chem. 2002, 79 (6), 819-825.

(35) Singh, J.; Kaur, L.; Singh, H. Food microstructure and starch digestion. In Advances in Food and Nutrition Research; Henry, J., Ed.; Academic Press: Cambridge, MA, 2013; Vol. 70, Chapter 4, pp 137- 179, DOI: 10.1016/ B978-0-12-416555-7.00004-7.

(36) Benmoussa, M.; Moldenhauer, K. A. K.; Hamaker, B. R. Rice amylopectin fine structure variability affects starch digestion properties. J. Agric. Food Chem. 2007, 55 (4), 1475-1479.

(37) Singh, J.; Dartois, A.; Kaur, L. Starch digestibility in food matrix: A review. Trends Food Sci. Technol. 2010, 21 (4), 168-180.

(38) Hardacre, A. K.; Lentle, R. G.; Yap, S.-Y.; Monro, J. A. Does viscosity or structure govern the rate at which starch granules are digested? Carbohydr. Polym. $2016,136,667-675$. 
(39) Kittipongpatana, O. S.; Kittipongpatana, N. Preparation and physicochemical properties of modified jackfruit starches. LWT- Food Sci. Technol. 2011, 44 (8), $1766-1773$.

(40) Shu, X.; Jia, L.; Ye, H.; Li, C.; Wu, D. Slow digestion properties of rice different in resistant starch. J. Agric. Food Chem. 2009, 57 (16), 7552-7559.

(41) Chen, P.; Wang, K.; Kuang, Q.; Zhou, S.; Wang, D.; Liu, X. Understanding how the aggregation structure of starch affects its gastrointestinal digestion rate and extent. Int. J. Biol. Macromol. 2016, 87, 28-33.

(42) Hasjim, J.; Ai, Y.; Jane, J.-I. Novel applications of amylose-lipid complex as resistant starch type 5. In Resistant Starch; Shi, Y.-C., Maningat, C. C., Eds.; John Wiley and Sons, Ltd.: Hoboken, NJ, 2013; Chapter 4, pp 79-94, DOI: 10.1002/9781118528723.ch4.

(43) Liu, H.; Ramsden, L.; Corke, H. Physical properties and enzymatic digestibility of phosphorylated ae, $\mathrm{wx}$, and normal maize starch prepared at different $\mathrm{pH}$ levels. Cereal Chem. 1999, 76 (6), 938-943.

(44) Escarpa, A.; González, M. C.; Mañas, E.; García-Diz, L.; Saura-Calixto, F. Resistant starch formation: Standardization of a high-pressure autoclave process. J. Agric. Food Chem. 1996, 44 (3), 924- 928. 